\title{
Retropubic Prostatectomy
}

National Cancer Institute

\section{Source}

National Cancer Institute. Retropubic Prostatectomy. NCI Thesaurus. Code C15401.

The surgical removal of all or part of the prostate gland through a lower abdominal (retropubic) incision. 